\title{
Assessing the cost-effectiveness of HPV vaccination strategies for adolescent girls and boys in the UK
}

\author{
Samik Datta ${ }^{1,2^{*}}$, Joshua Pink ${ }^{3}$, Graham F. Medley ${ }^{4}$, Stavros Petrou ${ }^{3}$, Sophie Staniszewska ${ }^{5}$, \\ Martin Underwood ${ }^{3}$, Pam Sonnenberg ${ }^{6}$ and Matt J. Keeling ${ }^{1}$
}

\begin{abstract}
Background: Human papillomavirus (HPV) is the most widespread sexually transmitted infection worldwide. It causes several health consequences, in particular accounting for the majority of cervical cancer cases in women. In the United Kingdom, a vaccination campaign targeting 12-year-old girls started in 2008; this campaign has been successful, with high uptake and reduced HPV prevalence observed in vaccinated cohorts. Recently, attention has focused on vaccinating both sexes, due to HPV-related diseases in males (particularly for high-risk men who have sex with men) and an equity argument over equalising levels of protection.

Methods: We constructed an epidemiological model for HPV transmission in the UK, accounting for nine of the most common HPV strains. We complemented this with an economic model to determine the likely health outcomes (healthcare costs and quality-adjusted life years) for individuals from the epidemiological model. We then tested vaccination with the three HPV vaccines currently available, vaccinating either girls alone or both sexes. For each strategy we calculated the threshold price per vaccine dose, i.e. the maximum amount paid for the added health benefits of vaccination to be worth the cost of each vaccine dose. We calculated results at $3.5 \%$ discounting, and also $1.5 \%$, to consider the long-term health effects of HPV infection.

Results: At 3.5\% discounting, continuing to vaccinate girls remains highly cost-effective compared to halting vaccination, with threshold dose prices of $£ 56-£ 108$. Vaccination of girls and boys is less cost-effective ( $£ 25-£ 53)$. Compared to vaccinating girls only, adding boys to the programme is not cost-effective, with negative threshold prices $(-£ 6$ to $-£ 3)$ due to the costs of administration. All threshold prices increase when using $1.5 \%$ discounting, and adding boys becomes cost-effective ( $£ 36-£ 47)$. These results are contingent on the UK's high vaccine uptake; for lower uptake rates, adding boys (at the same uptake rate) becomes more cost effective.
\end{abstract}

Conclusions: Vaccinating girls is extremely cost-effective compared with no vaccination, vaccinating both sexes is less so. Adding boys to an already successful girls-only programme has a low cost-effectiveness, as males have high protection through herd immunity. If future health effects are weighted more heavily, threshold prices increase and vaccination becomes cost-effective.

Keywords: HPV, Sexually transmitted infection, Human papillomavirus, Epidemiology, Modelling, MCMC, cost-effectiveness, Vaccination

\footnotetext{
*Correspondence: s.datta@warwick.ac.uk

'Zeeman Institute: SBIDER, Warwick Mathematics Institute and School of Life Sciences, The University of Warwick, Coventry CV4 8UW, UK

${ }^{2}$ National Institute of Water and Atmospheric Research, Wellington 6021, New

Zealand

Full list of author information is available at the end of the article
}

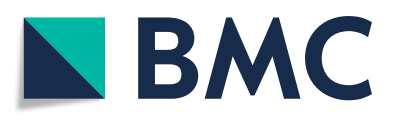

(c) The Author(s). 2019 Open Access This article is distributed under the terms of the Creative Commons Attribution 4.0 International License (http://creativecommons.org/licenses/by/4.0/), which permits unrestricted use, distribution, and reproduction in any medium, provided you give appropriate credit to the original author(s) and the source, provide a link to the Creative Commons license, and indicate if changes were made. The Creative Commons Public Domain Dedication waiver (http://creativecommons.org/publicdomain/zero/1.0/) applies to the data made available in this article, unless otherwise stated. 


\section{Background}

Human papillomavirus (HPV) is the world's most common sexually transmitted infection, with the majority of people being infected at some point in their lifetime $[1,2]$. At any time, up to $44 \%$ of sexually active women are infected $[3,4]$. Although for most people it is symptomless and they recover from the infection with no adverse effects, for a small proportion the infection may lead to adverse health sequelae. Of the 200 strains known and 120 catalogued thus far $[5,6]$, at least 18 have been labelled 'high-risk' HPV types due to their associations with development of different cancers [7]; in particular, strains 16 and 18 are associated with the majority of cervical cancers $[8,9]$. The high health and economic burden caused by HPV infection has led to many countries initiating HPV vaccinations campaigns.. Available vaccines include: a bivalent vaccine protecting against HPV-16 and HPV18 (Cervarix ${ }^{\circ}$ ) and a quadrivalent vaccine, which also protects against HPV-6 and HPV-11 (Gardasil ${ }^{\circ}$ ), both of which are linked to genital warts in both sexes [10]. A nonavalent vaccine (Gardasil $9^{\circ}$ ) has recently been approved for administration which, in addition to the aforementioned types, also protects against HPV types $31,33,45$, 52 , and 58. Uptake in different countries has varied considerably since the introduction of HPV vaccination. The United Kingdom (UK), which is the primary focus of this work, has relatively high national uptake rates of around 76-90\% [11]. Australia and Portugal also have relatively high uptake rates (70-80\%), while some countries such as the USA, France and New Zealand have low uptake (21-47\%) [12-15]. Some low and middle income countries such as Rwanda and Bhutan have also successfully set up programmes with extremely high reported uptake rates of 93-99\% [16, 17].

Vaccinating when young, before sexual debut, is optimal $[18,19]$. Early immunisation programmes targeted young teenage girls, with the focus on reducing incidence of cervical cancer later in life. In 2007, Australia targeted a wider age range of girls / women aged 12-26 as part of a limited catch-up programmes [20], and improvements in overall health outcomes have been shown in boys as well as girls due to indirect protection [21]. In the UK, teenage girls (aged 12-13) have been vaccinated in school since 2008, initially using the bivalent vaccine, replaced by the quadrivalent since 2011 [22]. National vaccination coverage has been consistently high since vaccination began, in the region of $76-90 \%[11,23]$, making the programme one of the most successful globally in combating HPV. A catchup programme for older girls was also implemented for three years (2008-2011), whereby 13-18 year old girls who missed out due to their age were also offered the vaccine [24]. Original models $[19,25]$ predicted it would be costeffective to vaccinate teenage girls, provided the duration of protection was at least ten years, as it would lower the incidence of subsequent health conditions arising from HPV infection, in particular cervical cancer, which is a major health burden [26]. Recently, the decision was made to reduce the three-dose schedule (two primers plus one booster) to two doses (one primer plus one booster), following immunological evidence for comparable efficacy $[27,28]$ and improved cost-effectiveness [29].

In 2011 Giuliano et al. [30] questioned whether or not it would be cost-effective to include additional target groups to vaccination programmes, given that the HPV vaccine is efficacious in both sexes. A 2016 meta-analysis by Brisson et al. [31] provides an overview of the herd effects of vaccinating girls. Studies have shown some groups to have relatively high prevalence of HPV and significant health effects, including HIV-positive individuals [32, 33], and men who have sex with men (MSM) $[34,35]$; the latter benefit less from the herd immunity generated by vaccinating girls than heterosexual men. Modelling has shown (as is intuitive) that increasing targets for vaccination, such as adding boys to a girls-only programme [18], and including adults [36], leads to further reductions in prevalence. However, in terms of cost-effectiveness, results of health economic analyses of contrasting programmes have generated less clear cut results. Most studies show vaccination of girls is highly cost-effective in many countries despite different cost-effectiveness thresholds for health improvements (e.g.[19, 37, 38], while the majority of studies that have proposed adding males to a female-only vaccination programme found it was less cost-effective compared to vaccinating only females [39, 40] and, in most cases, not cost-effective using standard thresholds of willingness to pay [24, 41-43]. A US study found that it would only be cost-effective if coverage in girls was around 20\% [44]. Research in Australia also showed a limited impact of boys' vaccination on HPV infections and related cancers in males [45], although Australia subsequently became the first country to adopt national gender-neutral vaccination of boys as well as girls [46]; New Zealand also added boys to the national programme in 2016. An analysis of vaccinating MSM in the USA found that it could be cost-effective, although it assumed the current vaccination programme in girls had no effect on HPV prevalence in MSM [47]. There thus remain many questions as to the cost-effectiveness of expanding the current girls-only strategy in the UK; we focus on the specific problem of adding teenage boys to the current vaccination programme.

Here we present an analysis of HPV infection and vaccination, to estimate the incremental cost-effectiveness of vaccinating boys as well as girls. The study consists of three parts: firstly, the fitting of parameters associated with HPV transmission, infection and recovery, by use of an epidemiological model incorporating sexual partnerships between individuals, matched to multiple HPV 
prevalence data sources. Secondly, the simulation of a range of vaccination strategies using the parameters from the above model. Thirdly, an economic analysis of the different strategies, taking into account the potential consequences (including health-related quality of life and cost implications) of HPV infections, to assess the costeffectiveness of each vaccination strategy. We have not included potential changes to the UK's cervical cancer screening service that might be precipitated by any future reduction in HPV prevalence. In this regard we follow the earlier analysis of female-only vaccination [19] and focus on the epidemiological and economic impacts of vaccination.

\section{Methods \\ Data \\ HPV prevalence data pre-vaccination}

To fit the transmission model to HPV prevalence rates before vaccination programmes were introduced, a variety of data, across a range of countries, was used. In total, results from 13 detailed epidemiological studies were used; information is given in Additional file 3: Table S1. Data consisted of either prevalence of serum antibodies against HPV types, or HPV DNA presence in the epithelial layer. The sex and age (groups) of individuals in each study were generally known, as well as, in the case of the studies by Nielson et al. [48] and Tanton et al. [49], sexual activity of individuals, and in the case of the study by King et al. [35], sexual orientation. These data were used to infer the infection parameters of our model including type-specific transmission probabilities.

\section{Partnership rates}

To model partnership behaviour of individuals, we used data from National Survey of Sexual Attitudes and Lifestyles (NATSAL) 2 and 3 [50]: UK-wide surveys of sexual behaviour. We fitted distributions to stratified data which allowed us to determine the annual rates of forming new sexual partners where there is unprotected intercourse, as well as the likely ages of these partners. Individuals were stratified by age, sex, sexual preference and previous sexual experience. For all simulations, we used NATSAL-2 distributions up to 2010, and NATSAL-3 distributions simulating forwards from 2010.

\section{Epidemiological model}

In the following section we describe the epidemiological model in brief; the transmission framework is explored in more detail in Datta et al. [50], and in Additional file 1: Appendix S1.

We used an individual-based modelling framework, with SIRS-V (Susceptible - Infected - Recovered - Susceptible - Vaccinated) dynamics, thus accounting for both short-duration natural immunity and longer-lasting protection due to vaccination. Populations of 50,000 individuals were generally modelled; this population size was a compromise between stochastic uncertainty and speed of the computationally intensive simulations. We used yearly data from Natsal-2 and Natsal-3 to determine distributions for the rates of new partnerships that involve unprotected sex and could therefore allow the spread of HPV [50]. Different distributions were defined depending on four personal characteristics: age (years), sex (male/female), sexual orientation (heterosexual/any other) and previous sexual experience (yes/no). Individuals in the population were given a risk-percentile, which determined the values extracted from the distribution of rates, with the distribution defined by the individual's characteristics (e.g. age, sex, etc). This meant that high risk-percentile individuals consistently had high rates of new partnerships relative to their peers. However, we know that individual behaviour patterns can change (e.g. by starting a long-term relationship); we therefore allowed risk-percentiles to be randomly redrawn with a low ageand sex-dependent probability - this allowed us to capture longer term (5-year and lifetime) behaviour from the NATSAL surveys.

The model was generally run for 100 years, allowing individuals to age, form new partnerships, become infected and recover. When an individual stochastically picked a new partner, the characteristics of the new partner were probabilistically determined by the status of the individual choosing. If the chosen partner was infected with one or more types of HPV, these could be stochastically transferred, with separate transmission probabilities for each type and with asymmetric transmission between the sexes [51]. Once infected, an individual had a rate of recovery, equal for all types, and may have generated a detectable serological response (separate probabilities for males and females) allowing us to match the model to serological data. After recovery, there was a period of strain-specific natural immunity before the individual became susceptible once more. In total, the model required fifteen HPV-specific parameters to be inferred from the empirical data.

We used 13 datasets to fit the parameters in the epidemiological model; the datasets used are listed in Additional file 3: Table S1. All data were either serological data (detecting the presence / absence of antibodies which the individual produced naturally after a previous or current infection), or DNA data (indicative of a current HPV infection). Although serological data were more widely available, the probability of producing antibodies following an infection is not high; probabilities are thought to be around $60 \%$ for females [52] and 30\% for males, although some studies report much lower type-specific rates[53]. These serological probabilities were inferred as part of the model-fitting process. DNA data, on the other 
hand, was considered more reliable, and we therefore assumed $100 \%$ sensitivity and specificity of these data. The model parameters were inferred using a Bayesian Markov Chain Monte Carlo (MCMC) framework and a standard Metropolis-Hastings algorithm. Likelihoods were generated by assuming that the data reflected a binomial sample of the model population.

\section{Simulating vaccination strategies}

For predicting the impact of vaccination, we followed the UK's Joint Committee on Vaccination and Immunisation (JCVI) guidelines and used the 'best' parameters from the model fitting (i.e. the mode from the posterior for each fitted parameter). We then estimated future levels of HPV in the population for different vaccination strategies. Although the parameters used for each run were identi$\mathrm{cal}$, due to the stochastic nature of the simulation, there was considerable variability between runs necessitating multiple simulations (500 runs per vaccination strategy). When simulating future vaccination scenarios, we used available uptake rates to simulate the girls-only vaccination that had occurred in the period 2008-2016 inclusive, using the bivalent vaccine until 2012, and quadrivalent after that $[11,54]$; we also took into account the catchup campaigns targeting girls aged 13-18 that occurred in 2008-11. (Uptake rates for both the routine and catchup campaigns are shown in Additional file 4: Table S2.) For both campaigns, we conservatively assumed that only girls who received all three HPV doses were protected. The three available vaccines, are each assumed to confer complete protection for their target types (16 and 18 for the bivalent vaccine; $6,11,16$ and 18 for the quadrivalent vaccine; and $6,11,16,18,31,33,45,52$ and 58 for the nonavalent vaccine) but differing levels of cross-protection to any remaining modelled HPV types (Additional file 5: Table S3). Forward simulations generated lifetime histories of individuals, for use in the economic analysis (see next section). Note that we assumed a two dose schedule (vaccine plus booster) for all future strategies, following evidence that this is likely to be more costeffective than three doses if vaccine protection is at least 20 years [29]. We assumed for simplicity that both doses were given simultaneously to individuals, and protection began immediately. Therefore we did not have to explicitly model the first dose.

The following vaccination strategies were simulated into the future, using the bivalent, quadrivalent or nonavalent vaccine. We define 'historical vaccination' as simulating girls-only vaccination for 2008-2016, with uptake rates for the main and catch-up programmes taken from UK data (Additional file 4: Table S2), and the respective new strategies began at the start of 2017:

1. Halted vaccination: historical vaccination, followed by a halting of all vaccination in 2017;
2. Girls: historical vaccination, followed in 2017 by selecting $85 \%$ of 12 -year-old females to be vaccinated at the start of each year (based on predictions from JCVI on future uptake rates);

3. Girls and boys: historical vaccination, followed in 2017 by selecting $85 \%$ of 12 -year old girls and $85 \%$ of 12 -year old boys to be vaccinated at the start of each year (this assumed that boys' uptake would be equal to that of girls);

4. Girls and boys equal: historical vaccination, followed in 2017 by selecting $42.5 \%$ of 12 -year old girls and $42.5 \%$ of 12 -year old boys at the start of each year to be vaccinated (hence an equal level of vaccination as girls' vaccination (strategy 2));

5. Girls naïve: no historical vaccination, and vaccinating $60 \%$ of 12 -year old girls from 2008 onwards;

6. Girls and boys naïve: no historical vaccination, and vaccinating $60 \%$ of 12 -year old girls and $60 \%$ of 12 -year old boys from 2008 onwards.

Halted vaccination was included, not as a plausible future strategy, but so that the threshold vaccine prices could be compared to a baseline (analogous to starting a new vaccination programme compared to not beginning one). The final three scenarios were designed to provide a scientific understanding of the generic conditions under which a gender-neutral vaccination programme would be cost-effective. Strategy 4 represents countries (like the UK) that have already commenced a girls-only vaccination programme (at varying uptake rates) and are interested in adding boys to the schedule; whilst strategies 5 and 6 represent countries which are yet to begin vaccinating against HPV. In such a way, we showed how impacts changed depending on both the coverage of vaccination in the population and existing herd immunity.

\section{Economic model}

The economic model took the form of a continuous time individual patient simulation (Additional file 2: Appendix S2), using output from the epidemiological model (specifically, times of infection and recovery, with each HPV type, for each individual in the model). The economic model then extrapolated these data to clinical events experienced by each individual over their lifetime (up to a maximum age of 100 years old). The healthcare costs and qualityadjusted life years (QALYs) for each vaccination strategy were compared to a baseline strategy (either no vaccination or girls only) and the incremental cost-effectiveness ratio of each strategy was estimated. We then generated the threshold vaccine dose price; that is, the maximum amount the healthcare system is willing to pay given the associated health benefits (currently set at $£ 20,000$ per QALY in the UK). Positive prices per vaccine dose below 
this threshold price will tend to generate positive net health benefits, whilst negative prices per vaccine dose offer no incentive to the manufacturer to provide the vaccine.

The economic evaluation was conducted from a UK National Health Service (NHS) and personal social services perspective with costs presented in pounds sterling (2013-14 prices). The following sections outline the basic clinical, cost and health utility parameters that fed into this economic model.

\section{Clinical parameters}

Age- and sex-specific incidences of the six cancer types included in the model (cervical, anal, vaginal, vulvar, penile, oropharyngeal), and cervical intraepithelial neoplasia were taken from 2013 UK cancer registration statistics. Age- and sex-specific incidences of genital warts were taken from a UK Health Protection Agency report [55], and age specific incidences of recurrent respiratory papillomatosis from a task force on recurrent respiratory papillomas [56].

Proportions of each of these clinical events associated with the HPV types included in the model were extracted from a published meta-analysis [57] and a literature review undertaken by Jit and colleagues [22] (Additional file 6: Table S4). It was often not possible to distinguish between events caused by types 6 and 11, so these were modelled as a single risk factor in the economic analysis. The same was true for events caused by types $31,33,45$, 52 and 58.

Data on disease incidence, proportion of disease associated with HPV, and age- and sex-stratified proportions of people infected with each HPV type pre-vaccination were combined to give annual event rates for the nine diseases included in the model, stratified by age, sex and current and past HPV infection status.

All-cause mortality data were taken from the Office of National Statistics [58], as were age-specific one and five year survival data for cervical cancer [59,60]. Data for other cancers were not available from the same source. Anal cancer survival rates were taken from an epidemiological study conducted by Jeffreys and colleagues [61], and those for other cancers from an Office for National Statistics report on survival rates from less common cancers [62]. However, since these data were old, the survival rates were adjusted to estimate contemporaneous values, using improvements in cervical cancer survival over the same time period. Mortality rates from recurrent respiratory papillomatosis were taken from a study by Bishai and colleagues [63]. For oropharyngeal cancer we use the proportion attributable to HPV from [64], and allow this proportion to increase up to $80 \%$ when sampling from economic parameters, to account for recent data [65].

\section{Health utilities}

Health utility decrements associated with cases of genital warts [66] and recurrent respiratory papillomatosis [63] were extracted from the literature. Health utility decrements associated with cancer consisted of two components, a short time loss during treatment, and a long term health utility decrement which persisted for the remainder of the individual's life.

\section{Costs}

Costs of recurrent respiratory papillomatosis [67], genital warts [68], and cervical cancer [69] were all taken from the literature and inflated to 2013-14 UK prices. Costs for other cancer types were not available for the UK. Therefore, the relative costs (compared to cervical cancer) for these cancers were estimated from the HPVADVISE model [22], and these were indexed against the cost of cervical cancer in the model to obtain estimates of cost for other cancer types. The cost of vaccination administration was assumed in the baseline analysis to be $£ 10$ per dose (Department of Health, personal communication), and we assumed a two dose schedule (vaccine plus booster) following evidence that this is likely to be more cost-effective than three doses if vaccine protection is at least 20 years [29]. Given the high level of completion in the UK, we assumed for simplicity that all immunised individuals were given both doses, hence calculating the costs and impact of vaccination was straightforward. If a significant fraction of the population only received one dose, this might skew both the health impacts and the associated costs; however, this is not the case in the UK in $2017 / 18,83.9 \%$ received two doses while just $5.2 \%$ only received one dose and $10.7 \%$ did not receive any vaccine.

The costs and health utility decrements used in the model are summarised in Additional file 7: Table S5.

\section{Time horizon and discounting}

The time horizon of the base case model was 100 years post the point where the different vaccine strategies affected individuals in the model. Thus, people who were born at the start of 2000 were included in the analysis, as were all subsequent newborns.

To comply with the JCVI's guidelines, two criteria were considered. Firstly, that for the most likely set of parameters (modes of posteriors) the mean discounted costs and outcomes should be evaluated against a $£ 20,000$ costeffectiveness threshold value for a QALY [70]. Secondly, to account for uncertainty, $90 \%$ of all posterior parameters should generate cost-effective results at a threshold of $£ 30,000$ per QALY. In both cases discounting at a rate of $3.5 \%$ per year (for both healthcare costs and QALYs) was used.

As an alternative scenario, we also evaluated the effects of applying a $1.5 \%$ discount rate to health impacts; this was 
in response to the CEMIPP report [71] which highlighted that $3.5 \%$ discounting was not always appropriate given disparate delays from infection time to health effects, and alternative discounting rates should be considered where appropriate. This is the case for HPV, when there may be many years between vaccination, infection and the onset of life-threatening cancers. 1.5\% was chosen in response to the appraisal by the National Institute of Care Excellence, which noted that "A discount rate of $1.5 \%$ for costs and benefits may be considered by the Appraisal Committee if it is highly likely that, on the basis of the evidence presented, the long-term health benefits are likely to be achieved" [70].

For the uncertainty criterion, we note that a single simulation contains stochasticity due to both parameter uncertainty, and also the finite size of the modelled population and the chance nature of transmission. Our results show that this second form of stochasticity is largely parameter invariant, and therefore we were able to separate these two effects (Supplementary Material). The results shown for the uncertainty analysis therefore reflect only our uncertainty in parameter estimates and not variability between simulations.

\section{Patient Involvement}

Patient and public involvement (PPI) in research has become embedded in health research with patients and the public involved as collaborative partners through the research process $[72,73]$. While common in health research, public involvement in mathematical and economic modelling is relatively rare, with few examples of embedded forms of collaborative involvement and a lack of agreed methodology for PPI in modelling.

For this analysis, patients and the public were not involved in developing either the research question or the design of the study in relation to the modelling approach, primarily because this is one of the first studies to include PPI in modelling. As such it is exploratory in nature, with our intention to identify the ways in which patients can contribute to modelling. We utilised the development of the HPV model as an opportunity to establish a PPI Reference Group (comprised of public members), to explore the potential for patients or the public to contribute to both the epidemiological and economic modelling components of the study, as part of the wider programme of work.

The Reference Group met regularly at key points in the study, with email contact in between. The wider aim of PPI within the project was to contribute towards conceptual development of PPI in mathematical and economic modelling, through the development of a new framework co-produced with patients and the public. Throughout the project we aimed to identify any impacts of the PPI Reference Group, and these will be disseminated through policy recommendations made by the Department of Health. A separate piece of work on the PPI contribution to the study is currently in progress.

\section{Results}

The fitting scheme produced well-defined parameter distributions (see Additional file 8: Figure S1 and Table S6), and simulating using the distributions provided good agreement between the model and data (see Additional file 9: Figures $S 2$ and S3). In the following sections the effects of varying vaccination strategy on HPV prevalence, incremental cost-effectiveness and the consequences for threshold vaccine dose prices, are presented.

\section{Epidemiological effects of vaccination strategies}

The predicted effect that a range of vaccination strategies would have on the prevalence of HPV is shown in Fig. 1.

The eight years of girls-only vaccination (2008-2016) had the effect of reducing HPV prevalence across the entire population (both male and female) from approximately $8 \%$ to $6.9 \%$. Assuming that girls-only vaccination continues at $85 \%$, by 2050 prevalence is predicted to drop to around $0.56 \%$ (yellow line). Adding boys' uptake at 85\% to the girls-only programme from 2017 onwards further reduces prevalence to approximately $0.13 \%$ (green line). As an alternative, keeping the number of vaccinations equal to the girls-only programme but splitting them equally between girls and boys (so that uptake is $42.5 \%$ in both sexes) leads to a less steep decline in prevalence, falling to around $1.5 \%$ by 2047 (blue line). Interestingly, halting vaccination entirely in 2017 leads to a continued fall in prevalence until 2025 (red line), due to the delay between vaccination and girls entering the sexually active population; however, in the longer term prevalence returns to approximately pre-vaccination levels.

As an alternative to the eight years of girls-only vaccination at high uptake, we investigated the effect of a lower uptake HPV vaccination campaign from 2008. Vaccinating just $60 \%$ of girls leads to a less marked decline in prevalence, reducing to around $2.5 \%$ by 2050 (black solid line); vaccinating $60 \%$ of both sexes further reduces the prevalence to $0.31 \%$ (black dashed line).

We note that, due to basing pre-2010 individuallevel behaviour on Natsal-2 and post-2010 behaviour on Natsal-3 which reported marginally increased sexual behaviour [74], we observe slight increases in baseline prevalences from 2010 onwards. This can be seen most easily by contrasting prevalence pre-vaccination with values at 2050 for halted vaccination $(7.97 \%$ and $8.02 \%$ respectively).

These results have two important public-health implications. Firstly the reduction in cases from adding boys to the vaccination program is markedly less that the initial impact of adding girls. Secondly, a gender-neutral campaign vaccinating $60 \%$ of the population has comparable 


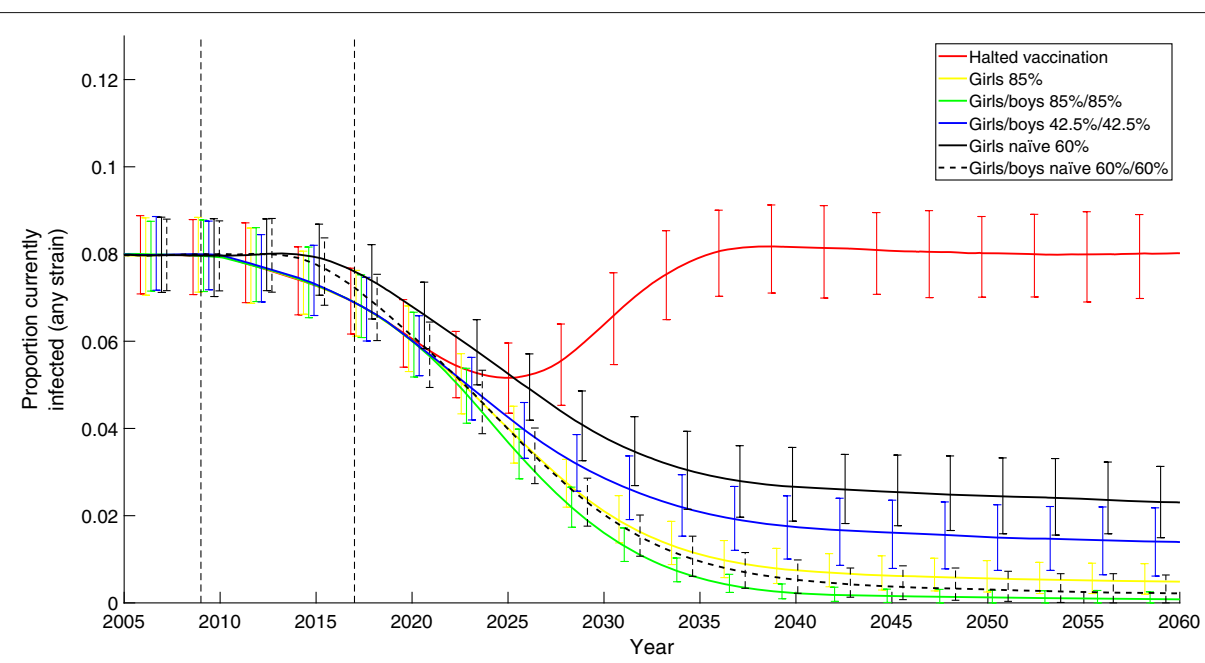

Fig. 1 The effects of different vaccination strategies on the prevalence of HPV in the population, over the 30 years following a change in strategy. Strategies tested include: halted vaccination (red), girls only at $85 \%$ (yellow), girls/boys at $85 \% / 85 \%$ (green), girls/boys at $42.5 \% / 42.5 \%$ (blue), girls at 60\% from 2008 (black solid), and girls/boys at 60\%/60\% from 2008 (black dashed). All strategies use the nonavalent vaccine

impact on infection prevalence as vaccinating $85 \%$ of girls (42.5\% of the population). Given the heterosexual nature of the majority of the UK population, it is clear that vaccination of girls is generating considerable herd-immunity for boys.

A detailed breakdown in the prevalence of different HPV strains, by age and gender, under alternative vaccination strategies is given in Additional file 11: Table S7. As might be expected, strains decrease according to the level of protection afforded by the vaccine as in Additional file 5: Table S3; for example, as strains 6 and 11 are not covered by the bivalent vaccine, prevalences of these strains are comparable between the strategies of halted, girls-only bivalent and gender-neutral bivalent vaccination. If the strain is covered by the vaccine, girls-only vaccination reduces strain prevalence significantly compared to halted vaccination, while adding boys to the girls-only programme has a more limited effect (e.g. for 26-35 year old males, strains 31/33/45/52/58 and the nonavalent vaccine, girls-only vaccination reduces prevalence from $10.2 \%$ to $2.05 \%$; gender-neutral vaccination reduces prevalence to $0.658 \%$, a lower incremental benefit).

\section{Cost-effectiveness of vaccination strategies}

The mean results of the cost-effectiveness model are shown in Fig. 2 and Table 1, with the distribution of threshold prices shown in Additional file 10: Figure S4. Threshold dose prices for cost-effectiveness, using both $3.5 \%$ and $1.5 \%$ discounting, with a $£ 20,000$ costeffectiveness threshold value, are shown for all vaccination strategies versus halted vaccination, and for genderneutral strategies versus girls only. Prices are shown for the cost per dose, assuming a two-dose schedule, and a $£ 10$ administration charge for each dose.

Vaccinating girls only or both girls and boys, with any of the vaccines, was always cost-effective compared to not vaccinating, with positive threshold dose prices and positive confidence intervals in all instances. However, vaccinating girls alone was more cost-effective per dose, with a higher threshold price for each vaccine, compared to a gender-neutral strategy. Generally, the nonavalent vaccine was the most effective in preventing disease, followed by the quadrivalent, and finally the bivalent, as would be expected from the level of protection offered, hence a greater threshold price. Incremental to a girls-only vaccination campaign, adding boys gave threshold dose prices very close to, but below, zero, at $3.5 \%$. The results from individual simulations varied widely and 500 replicates were needed to achieve relatively tight confidence intervals around the mean. For the quadrivalent vaccine, the mean dose price was negative (at $-£ 2.92$ ) and, given that the confidence intervals are below zero (from $-£ 3.64$ to $-£ 2.18$ ), we can say with $95 \%$ confidence that the threshold price is negative. The same arguments apply to both the bivalent and nonavalent vaccines.

At $1.5 \%$ discounting all threshold prices increased, but with the same qualitative patterns; for girls-only vaccination compared to halted vaccination threshold prices were $£ 687$ - $£ 811$ for the three vaccines and gender-neutral vaccination was less cost-effective, with threshold prices of $£ 362-£ 429$. Incremental to girls only, gender-neutral vaccination had positive threshold prices of $£ 36-£ 47$. This is due to the lower discount rate adding more weight to economic values placed on health conditions in the future. In 


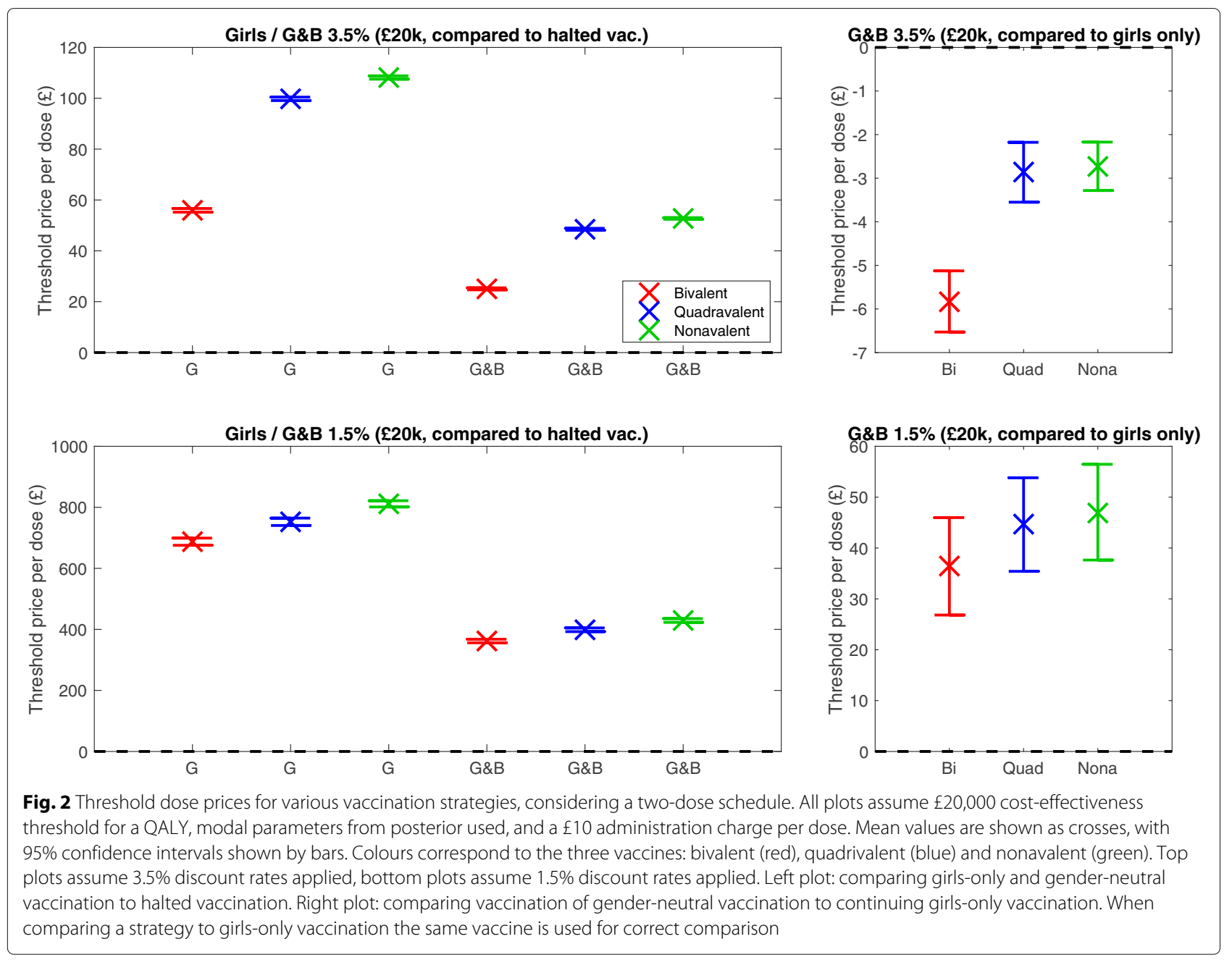

general, a lower discounting rate will always make vaccination more cost-effective for infections like HPV, where the health consequences are experienced years or decades after infection.

A detailed breakdown in the reduction in cases of the health sequelae under alternative vaccination strategies is given in Additional file 12: Table S8. As might be expected, there is a large decrease in cases of health sequelae when vaccinating girls compared to halted vaccination, while adding boys to the girls-only programme yields a much smaller decrease in cases. Incremental cost-effectiveness ratios (ICERs) for alternative vaccination strategies are shown in Additional file 13: Tables S9 and S10, and Figure $\mathrm{S} 5$, at a range of assumed vaccine dose prices. Relative

Table 1 Threshold dose prices for various vaccination strategies, considering a two-dose schedule

\begin{tabular}{lllll}
\hline Vaccination strategy & $£$, versus halted vac. (3.5\%) & $£$, versus girls' vac. (3.5\%) & $£$, versus halted vac. (1.5\%) & $£$, versus girls' vac. (1.5\%) \\
\hline Girls, bivalent & $55.80(55.04-56.57)$ & - & $687.47(675.62-699.20)$ & - \\
Girls, quadrivalent & $99.64(98.90-100.37)$ & - & $752.46(740.51-764.72)$ & - \\
Girls, nonavalent & $108.05(107.36-108.75)$ & - & $811.44(801.18-821.68)$ & - \\
Girls \& boys, bivalent & $25.08(24.64-25.52)$ & $-5.67(-6.42--4.93)$ & $361.99(356.09-367.85)$ & $36.46(26.82-45.98)$ \\
Girls \& boys, quadrivalent & $48.38(47.95-48.80)$ & $-2.92(-3.64--2.18)$ & $398.68(392.65-404.84)$ & $44.70(35.42-53.81)$ \\
Girls \& boys, nonavalent & $52.77(52.42-53.10)$ & $-2.56(-3.13--1.99)$ & $429.26(422.98-435.44)$ & $46.88(37.63-56.46)$ \\
\hline
\end{tabular}

Mean values shown over 500 simulations, with 95\% confidence intervals in brackets. All strategies assume a $£ 20,000$ cost-effectiveness threshold for a QALY, with both 3.5\% and $1.5 \%$ discount rates applied, and a $£ 10$ administration charge per dose. When comparing a strategy to girls-only vaccination the same vaccine is used for correct comparison 
to halted vaccination, girls-only vaccination results in lower ICERs than a gender-neutral programme (Additional file 13: Tables S9), while ICERs are significantly higher for a gender-neutral programme compared with girls-only vaccination, signalling low cost-effectiveness (Additional file 13: Tables S10).

Employing the probabilistic approach as per the JCVI's guidelines, whereby parameters in both the transmission and economic models were sampled from appropriate distributions, and increasing the cost-effectiveness threshold for a QALY to $£ 30,000$, the threshold dose prices at the 10th percentile of simulated values (for bivalent, quadrivalent and nonavalent vaccines, and at both $3.5 \%$ and $1.5 \%$ discount rates) are shown in Table 2, and the cumulative distribution of threshold dose prices are displayed in Fig. 3.

It is evident that, while vaccination of girls fulfilled the JCVI criterion of $90 \%$ of simulations generating costeffective results (Fig. 3a), adding boys to an existing girlsonly campaign at $3.5 \%$ discounting did not satisfy the condition (Fig. 3b). For all three vaccines, the $10 \%$ boundary in the cumulative distribution for threshold dose price lay below zero - meaning that, by the JCVI guidelines for uncertainty, adding boys is not cost-effective - further supporting the conclusion from the results using the most likely parameters.

Conversely, at $1.5 \%$ discounting (Fig. 3c) all three vaccines had positive values at the $10 \%$ boundary ( $£ 45-£ 67$ ). Hence at $1.5 \%$ both criteria for cost-effectiveness are met. We note that the $10 \%$ boundary price for the quadrivalent vaccine is higher than for the nonavalent (at both 3.5\% and $1.5 \%$ discounting). We suggest this is because vaccinating girls only with the nonavalent vaccine induces herd immunity against all 9 HPV types such that the addition of vaccinating boys has limited impact; in contrast, given that the quadrivalent vaccine induces only limited herd immunity against types $31,33,45,52$ and 58 , including vaccination of boys has a more substantial impact on these types.

Considering the different levels of vaccine uptake in more detail and the resulting herd-immunity provides a richer understanding of the cost-benefit relationship (Fig. 4). Two elements contributed to the low threshold dose price previously described. The first is that, as the uptake rate of vaccination in both boys and girls increased, so the threshold dose price decreased; this is because of the herd immunity generated by immunising an increased proportion of girls such that much of the vaccination in boys was effectively "wasted", i.e. the majority of men who were vaccinated as adolescents will not be subsequently exposed to infection. The second is that the high vaccination uptake rates observed so far in the UK, have already generated such high levels of population protection that the impact of vaccinating boys was further reduced (Fig. 4, circle markers compared to square markers). Thus, if uptake is expected to be low across a population, then introducing a gender-neutral scheme early is expected to be highly beneficial; for example, at 3.5\% discounting and assuming uptake was just $10 \%$, the mean threshold price for adding boys was $£ 112.37$ (111.35 - 113.40) without prior vaccination or $£ 78.11$ (76.60 - 79.58) if girls had been vaccinated for eight years as assumed elsewhere in this paper.

We note that, using 3.5\% discounting (Fig. 4a), at $85 \%$ uptake (dashed vertical line) the cost-effectiveness of gender-neutral vaccination drops below zero for a population with UK vaccination up until present, whereas it is positive for a vaccination-naïve population. As with the previous simulations, decreasing the discounting rate to $1.5 \%$ increases all threshold prices (Fig. $4 \mathrm{~b}$ ), with positive prices up to and including $90 \%$ uptake rates.

\section{Discussion}

The modelling work performed here combined epidemiological and economic insights with advice from our PPI group, and provides cost-effectiveness results for a variety of vaccination strategies to combat HPV, following standard methodologies (e.g. [19, 26, 75-77]. Previous studies have predicted that vaccination of girls would be highly cost-effective $[19,26,75]$, with concomitant decreases in levels of HPV infection (and associated adverse health sequelae) $[9,10,78-80]$. The majority of

Table 2 The threshold dose prices at the 10th percentile of simulated epidemiological and economic values (over 500 simulations), using both $3.5 \%$ and $1.5 \%$ discount rates and an increased cost-effectiveness threshold of $£ 30,000$, compared to both halted vaccination and girls-only vaccination, with a $£ 10$ administration charge per dose

\begin{tabular}{lllll}
\hline Vaccination strategy & $£$, versus halted vac. (3.5\%) & $£$, versus girls' vac. (3.5\%) & $£$, versus halted vac. (1.5\%) & $£$, versus girls' vac. (1.5\%) \\
\hline Girls, bivalent & 68.07 & - & 1024.71 & - \\
Girls, quadrivalent & 140.85 & - & 1121.74 & - \\
Girls, nonavalent & 147.90 & - & 1232.70 & - \\
Girls and boys, bivalent & 32.13 & -6.38 & 577.45 & 45.06 \\
Girls and boys, quadrivalent & 74.95 & -4.84 & 654.07 & 67.12 \\
Girls and boys, nonavalent & 81.12 & -6.04 & 676.54 & 49.89 \\
\hline
\end{tabular}



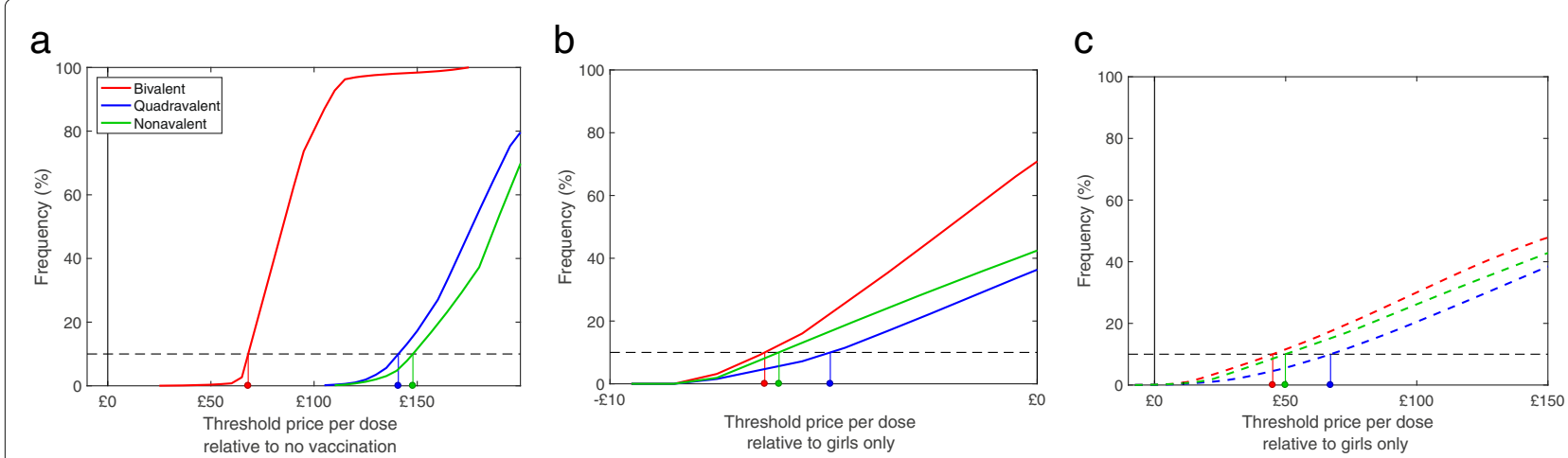

Fig. 3 Threshold dose prices for girls-only vaccination compared to halted vaccination (at 3.5\% discounting, left plot), and gender-neutral vaccination compared to girls-only vaccination (at 3.5\% discounting, middle plot, and at $1.5 \%$ discounting, right plot). Coloured lines show different vaccines: bivalent (red), quadrivalent (blue) and nonavalent (green). Threshold dose prices at the 10 th percentile of simulated values highlighted by coloured lines from $x$-axis to curve. Vertical black dashed line indicates $£ 0$ threshold price. Results shown for 500 simulations

previous economic analyses indicated that adding boys to the girls-only programme is unlikely to be cost-effective (e.g. [24, 26, 43, 45, 81]. The results presented here echo these findings, but provide both a UK-specific context and a broader scientific understanding of the impact of vaccine uptake and economic discounting.

Our fitted epidemiological model provides a good match to the available datasets. The use of likelihoodbased techniques and Bayesian MCMC methodology meant that we could account both for inconsistencies between data sets and uncertainty in parameter estimates. In particular, while parameter estimates for the main HPV types $(6,11,16$ and 18) are well defined, there is greater uncertainty surrounding the additional five types in the nonavalent vaccine $(31,33,45,52$ and 58$)$, reflecting the sparsity of data sources (Additional file 9: Figures S2 and S3). A lower probability of serological response in men compared to women is in agreement with a recent metaanalysis on natural immunity [82]; although that study found immune period difficult to determine due to a lack of knowledge of infection time, our model suggests a period of around 1.4 years.

Vaccination of girls has been observed to lower the population prevalence of HPV $[11,80]$, and our models suggest that in the UK this trend is likely to continue (Fig. 1, yellow line). Even if vaccination is stopped, the time-delay between vaccinating young girls and them entering the sexually active population means that prevalence will continue to fall for another nine years before finally returning to pre-vaccination levels of around 9.5\% (for any of the
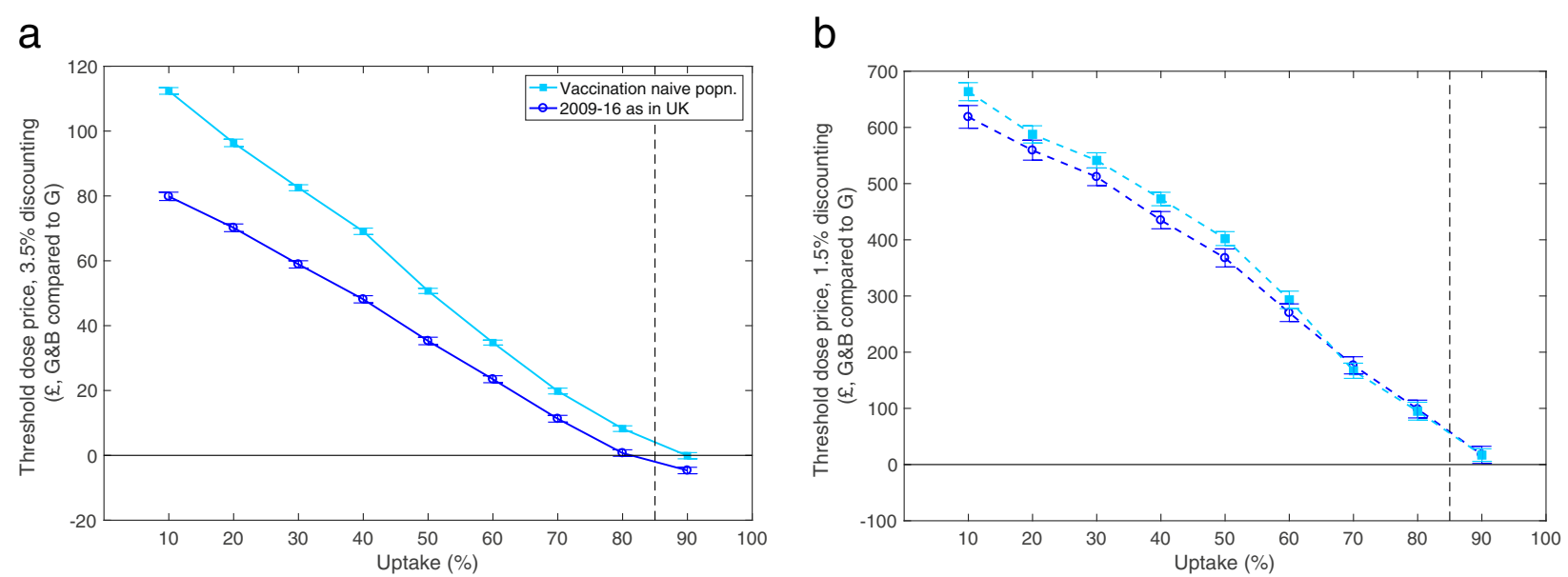

Fig. 4 The mean threshold vaccine dose price for gender-neutral vaccination compared to girls-only vaccination, using the quadrivalent vaccine, for a 3.5\% discounting and $\mathbf{b} 1.5 \%$ discounting. Two initial conditions are tested: assuming no vaccination has previously occurred (square markers), or assuming uptake in girls as in the UK historically for 2008-2016 (circle markers). 95\% confidence intervals shown for all points. Vertical dashed line highlights $85 \%$ uptake, which is the rate assumed for girls-only and gender-neutral vaccination in the future in this paper. 200 simulations carried out for each data point shown 
nine types modelled here). A girls-only vaccination campaign with $85 \%$ uptake with the nonavalent vaccine is expected to reduce population prevalence to around 1\% within forty years. This value is further reduced to just $0.2 \%$ if boys are also included in the vaccination scheme. Therefore, we find that while introducing vaccination in young girls leads to a reduction in prevalence of around $90 \%$, adding boys to this scheme only provides a limited further reduction in prevalence. Given that the majority of HPV transmission is through heterosexual relationships (so the infection must pass through a male-female-malefemale ...chain), it is clear that completely protecting either sex is sufficient to halt heterosexual transmission. This helps to explain why adding boys to an effective girls-only programme has limited effect. The exception to this is MSM, where there is limited herd-immunity from the girls-only programme, and so vaccination could be expected to be highly effective [34, 35, 47]. However, a mass (i.e. untargeted) vaccination programme of boys does not target this group.

In general, any additional vaccination will always reduce the prevalence of infection and hence the expected amount of disease; furthermore, greater reductions are naturally predicted for vaccines that provide protection against more HPV types. To understand whether these declines are worth the additional costs of vaccination, requires us to undertake a health economic evaluation comparing health benefits against vaccine-related costs and associated costs. All tested strategies were costeffective (at the $£ 20,000$ cost-effectiveness threshold for a QALY and assuming 3.5\% annual discounting) compared to halted vaccination. Girls-only vaccination was highly cost-effective versus halted vaccination, with threshold dose prices of $£ 55.80$, $£ 99.64$ and $£ 108.05$ for the bivalent, quadrivalent and nonavalent vaccines, respectively (Table 1). Gender-neutral vaccination was also costeffective versus halted vaccination, although at lower threshold dose prices of $£ 25.08, £ 48.38$ and $£ 52.77$ for the three respective vaccines. All threshold prices were higher at $1.5 \%$ discounting, but the same qualitative pattern observed (Table 1).

Comparing gender-neutral vaccination with girls-only vaccination (that is the cost-effectiveness of adding boys), none of the vaccines had a positive dose threshold price at $3.5 \%$ discounting (- $£ 5.67,-£ 2.92$ and $-£ 2.56$ for the three vaccines), with confidence intervals that were all below zero (Table 1). Moreover, following UK guidelines for economic evaluations of immunisation programmes, we examined the uncertainty in our predictions. Even removing between-simulation stochasticity, the uncertainty in parameter estimates was such that there is a less than $10 \%$ chance that gender-neutral vaccination is cost-effective (compared to girls-only) at a cost-effectiveness threshold value for a QALY as high as $£ 30,000$ (Fig. 3b). In contrast, when comparing all strategies to halted vaccination, the recommended probabilistic threshold is always achieved (Table 2).

At 1.5\% discounting all threshold dose prices increase, and gender-neutral vaccination, incremental on girlsonly vaccination is cost-effective, with threshold prices of $£ 36.46, £ 44.70$ and $£ 46.88$ (Table 1). There is also a greater than $90 \%$ chance that gender-neutral vaccination is costeffective (compared to girls-only) at a cost-effectiveness threshold value of $£ 30,000$ per QALY (Fig. 3c). Recent recommendations from the CEMIPP report [71] and the JCVI [83] suggest applying a lower discount rate to the health effects of HPV vaccination, given the long time delay between infection and the onset of adverse sequelae.

There is some empirical evidence of cross-protective effects of the bivalent vaccine against warts-causing types 6 and $11[10,84]$. Although we have not tested the assumption here, the fact that the quadrivalent and nonavalent vaccines (which offer complete protection against 6 and 11) are not cost-effective for a gender-neutral programme at $3.5 \%$ discounting, means that adding these cross-protective effects will not change the conclusions reached.

As vaccine coverage in girls increases, so herdimmunity builds up, making additional vaccination less worthwhile. Hence, with higher uptake rates in girls (and longer historical vaccination of girls), boys' vaccination becomes less cost-effective (Fig. 4). This is a critical result, as it shows that in the UK, where uptake in girls has historically been so high $[11,54]$ adding boys is not a cost-effective option. Conversely, in other countries where existing girls-only programmes have lower uptake rates (such as the USA and France [13]) adding boys may indeed still be cost-effective. This is due to the higher prevalence of infection remaining in the population, leading to potentially more significant declines in the incidence of adverse health effects such as cervical and oropharyngeal cancer. Similarly, including boys in the vaccination scheme can buffer the programme against fluctuations in level of vaccine uptake [85]. This impact of uptake in girls, echoes previous findings. Given the significant variation in uptake of the girls' programme between countries [12], we would expect to observe a threshold below which gender-neutral vaccination was economically acceptable; however, the reality is more ambiguous. In particular, Australia, New Zealand and Canada have recently added boys to their respective national vaccination programmes, and uptake rates are $71 \%$ [13], 40-56\% [13, 15] and 39-89\% $[86,87]$ in these respective countries. For New Zealand this contradicts a recent study which found that adding boys would not be cost effective [43]. Clearly, these health economic arguments are strongly influenced by the vaccine price, with recent reductions in average tender prices favouring the adoption of a gender-neutral programme [88]. 
Girls carry a larger economic burden of HPV-related disease than boys [89], due to the relatively high incidence of cervical cancer, so they are always the primary target for vaccination. This is evidenced in Additional file 12: Table S8, where the incidence of cervical cancer with halted vaccination is higher than all cancers except for oropharyngeal cancer. The addition of boys' vaccination gives small reductions in prevalence of these health effects, in comparison to vaccinating girls alone. Combining the incidence rates in Additional file 12: Table S8 with the costs and QALY decrements in Additional file 7: Table S5, we calculate the main cost-saving impact of adding boys is reductions in oropharyngeal cancer and genital warts, with cervical cancer reduction having reduced savings. In low uptake countries, questions remain as to whether it would be more cost-effective to vaccinate boys or to try to increase the coverage in girls, with more studies suggesting the latter [39]. Recent work, however, has highlighted the increasing importance of other cancers as HPV vaccination programmes lead to declines in cervical cancer cases [90].

It is clear from our analysis that mixing patterns are an important factor in the spread of HPV. An aspect not explicitly modelled here was the possibility of disease import from outside the population (i.e. immigration and tourism). This has been considered in some of our work, but unprotected sex with unvaccinated individuals from outside the UK is likely to be a relatively minor component [91]. It is also likely to be highly non-random in a way in which there is little data to support any assumption.

One limitation of our modelling approach is the decoupling of HPV vaccination from cervical cancer screening we have implicitly assumed throughout this work that cervical cancer screening will continue in its current form. It is possible that the nature of (and hence costs and consequences of) the cervical cancer screening programme will change in the future. In the near term this is most likely to be caused by evidence showing HPV-based cervical screening is more effective than the current cytologybased programme, and supports increasing the screening intervals from three to five years [92]. A programmatic change to primary HPV testing for cervical cancer is predicted to reduce cervical cancer incidence [93]; this has the potential to reduce the estimated cost-effectiveness of HPV vaccination in the UK. On the other hand, screening programmes could change directly as a result of the HPV vaccination programme; it has been estimated that the successful use of the bivalent vaccine could reduce the need for more than three cervical smears per lifetime [94]. A recent study from Australia concluded that, if continued gender-neutral vaccination was maintained into the future, cases of cervical cancer could reduce from seven cases per 100,000 women to less than four by 2028 [95]. Overall, while the current cervical screening programme is implicitly accounted for in our study (ignoring any possible fluctuations in screening participation by year/age/vaccination status), we do not account for the impact of future changes to screening technology, interval and compliance. Thus, far more research is needed to inform best policy on the interaction between HPV vaccination and cervical cancer screening. Future changes to the cervical cancer screening programme are beyond the remit of this study, but are an important area of focus for future research.

A key assumption in our models, which may require further study is that vaccination is an independent random process, and in particular is not correlated with sexual behaviour. If this is not appropriate, it may be that the girls who are missing out on vaccination are in the highest risk groups, and may be disproportionately contributing to transmission of HPV. Due to the high prevalence of HPV across both men and women [96-98], this seems unlikely to have a significant effect on the dynamics of infection, although other modelling studies have shown that the correlation does not need to be big to have an impact [99]. Whilst there is no clear consensus of drivers of vaccine uptake at a community-level [12], there is more evidence at the individual level of a relationship between vaccination and risk behaviour [100, 101]. When risk is highly clustered to particular groups, for example for hepatitis-B, then the ability to target these groups becomes critical to the decision to vaccinate [102]. An important follow-up to this work would be to assess the importance of low- and high-risk infection groups, their likelihood of vaccination, the mixing between the two groups, and the effectiveness of vaccination given the relative coverage in the high-risk group.

\section{Conclusions}

The generic conclusion from this work is that as coverage in girls increases, there is less incremental benefit from adding boys to the programme, due to existing herdimmunity. In the case of the UK, with the highest reported sustained HPV vaccine uptake rates in girls of any country, it is unlikely that adding boys will be cost-effective within standard economic guidelines which assume a 3.5\% economic discounting. However, given the long time-scales associated with HPV infection and resulting disease, it may be more appropriate to adopt a $1.5 \%$ discounting, in which case adding boys to the programme becomes cost-effective for all three vaccines considered.

\section{Additional files}

Additional file 1: Appendix S1. A detailed overview of the key assumptions underpinning the epidemiological model employed in the paper. (PDF $70 \mathrm{~kb}$ )

Additional file 2: Appendix S2. Economic model assumptions. (PDF 40 kb) 
Additional file 3: Table S1. A summary of the datasets used to fit the HPV transmission model to for pre-vaccination populations. (PDF $53 \mathrm{~kb}$ )

Additional file 4: Table S2. Vaccine uptake in the UK, 2008-2016. (PDF $746 \mathrm{~kb}$ )

Additional file 5: Table S3. Efficacy of the three HPV vaccines against different HPV types. (PDF $48 \mathrm{~kb}$ )

Additional file 6: Table S4. Clinical parameter values and sources. (PDF 50 $\mathrm{kb})$

Additional file 7: Table S5. Costs and health utility decrements. (PDF 55 $\mathrm{kb})$

Additional file 8: Figure S1 and Table S6. Parameter distributions. (PDF $176 \mathrm{~kb})$

Additional file 9: Figures S2 and S3. Comparing HPV prevalence between the model and data. (PDF $328 \mathrm{~kb}$ )

Additional file 10: Figure $\mathrm{S4}$. The mean threshold price per dose, under different vaccination strategies, for the base case scenario, at both 3.5\% and $1.5 \%$ discount rate. (PDF $154 \mathrm{~kb}$ )

Additional file 11: Table S7. The mean prevalence of different HPV strains (as a percentage) in different ages and genders, after 50 years of simulating a range of vaccination strategies. (PDF $51 \mathrm{~kb}$ )

Additional file 12: Table $\mathrm{S} 8$. Cases of disease for different vaccination strategies. (PDF $1254 \mathrm{~kb}$ )

Additional file 13: Tables S9 and S10, and Figure S5. Incremental cost-effectiveness ratios. (PDF $146 \mathrm{~kb}$ )

\section{Abbreviations}

HPV: Human papillomavirus; ICER: Incremental cost-effectiveness ratio; JCVI: Joint Committee on Vaccination and Immunisation; MCMC: Markov Chain Monte Carlo; MSM: Men who have sex with men; NATSAL: National Survey of Sexual Attitudes and Lifestyles; NHS: National Health Service; PPI: Patient and public involvement; QALY: Quality-adjusted life year; SIRS-V: Susceptible Infected - Recovered - Susceptible - Vaccinated; UK: United Kingdom

\section{Acknowledgements}

We would like to thank colleagues at the Department of Health for their useful suggestions and assistance with various aspects of developing the epidemiological and economic models, in particular Peter Grove and Geoff Wootton. We also extend thanks to the members of the JCVI HPV subcommittee for extremely useful feedback on early iterations of the manuscript, especially Jonathan Crofts and Andrew Earnshaw. Finally, we would also like to extend our thanks to the referees who provided detailed feedback on a previous draft of this manuscript.

\section{Funding}

The work was supported by the UK Department of Health [grant number 027/0089]. The funder had no role in the study design; in the collection, analysis and interpretation of data; in the writing of the manuscript; and in the decision to submit the article for publication. The views expressed are those of the authors and not necessarily those of the Department of Health. All authors had access to all data in the study and can take responsibility for the integrity of the data and the accuracy of the data analysis.

\section{Availability of data and materials}

Data sharing is not applicable to this article as all data used were taken from previously published literature.

\section{Authors' contributions}

SD acquired and cleaned the epidemiological data, designed the epidemiological model and the statistical fitting scheme, and drafted and revised the paper. He is guarantor. JP acquired and cleaned the economic data, designed the economic model, and drafted and revised the paper. GFM advised on the epidemiological model design, and revised the draft paper. SP assisted with the economic analysis, and revised the draft paper. SS oversaw PPI elements of the work, and revised the draft paper. MU revised the draft paper. PS assisted with interpreting the Natsal data, and revised the draft paper. MJK oversaw design of the epidemiological model, revised the draft paper, and is PI for the project. All authors read and approved the final manuscript.

\section{Ethics approval and consent to participate} Not applicable.

\section{Consent for publication}

Not applicable.

\section{Competing interests}

The authors declare that they have no competing interests. MU is Chief Investigator or co-applicant on multiple research projects funded by NIHR, and a journal editor for NIHR for which he receives a fee; MU is director and shareholder of Clinvivo Ltd.

\section{Publisher's Note}

Springer Nature remains neutral with regard to jurisdictional claims in published maps and institutional affiliations.

\section{Author details}

${ }^{1}$ Zeeman Institute: SBIDER, Warwick Mathematics Institute and School of Life Sciences, The University of Warwick, Coventry CV4 8UW, UK. ${ }^{2}$ National Institute of Water and Atmospheric Research, Wellington 6021, New Zealand. ${ }^{3}$ Warwick Clinical Trials Unit, Warwick Medical School, The University of Warwick, Coventry CV4 8UW, UK. ${ }^{4}$ Department for Global Health and Development, London School of Hygiene and Tropical Medicine, London WC1H 9SH, UK. ${ }^{5}$ Royal College of Nursing Research Institute, Warwick Medical School, The University of Warwick, Coventry CV4 8UW, UK. ${ }^{6}$ Research Department of Infection and Population Health, University College London, London WC1E 6JB, UK.

Received: 23 December 2018 Accepted: 17 May 2019

Published online: 24 June 2019

\section{References}

1. Koutsky L. Epidemiology of genital human papillomavirus infection. Am J Med. 1997;102(5):3-8.

2. Baseman JG, Koutsky LA. The epidemiology of human papillomavirus infections. J Clin Virol. 2005;32:16-24

3. Bosch FX, De Sanjosé S. Chapter 1: Human papillomavirus and cervical cancer-burden and assessment of causality. JNCI Monogr. 2003;2003(31):3-13.

4. Richardson $H$, Kelsall G, Tellier P, Voyer $H$, Abrahamowicz M, Ferenczy A, Coutlée F, Franco E. The natural history of type-specific human papillomavirus infections in female university students. Cancer Epidemiol Biomark Prev. 2003;12(6):485-90.

5. Bernard $\mathrm{H}-\mathrm{U}$. The clinical importance of the nomenclature, evolution and taxonomy of human papillomaviruses. J Clin Virol. 2005;32:1-6.

6. Intlekofer KA, Cunningham MJ, Caplan AL. The HPV vaccine controversy. Virtual Mentor. 2012;14(1):39.

7. Trottier H, Franco E. The epidemiology of genital human papillomavirus infection. Vaccine. 2006;24:4-15.

8. Kohli M, Ferko N, Martin A, Franco E, Jenkins D, Gallivan S, Sherlaw-Johnson C, Drummond M. Estimating the long-term impact of a prophylactic human papillomavirus 16/18 vaccine on the burden of cervical cancer in the UK. Br J Cancer. 2007;96(1):143-50.

9. Lehtinen M, Paavonen J, Wheeler CM, Jaisamrarn U, Garland SM, Castellsagué X, Skinner SR, Apter D, Naud P, Salmerón J, et al. Overall efficacy of HPV-16/18 AS04-adjuvanted vaccine against grade 3 or greater cervical intraepithelial neoplasia: 4-year end-of-study analysis of the randomised, double-blind PATRICIA trial. Lancet Oncol. 2012;13(1): 89-99.

10. Howell-Jones R, Soldan K, Wetten S, Mesher D, Williams T, Gill O, Hughes $G$. Declining genital warts in young women in England associated with HPV 16/18 vaccination: an ecological study. J Infect Dis. 2013;208(9):1397-403.

11. Public Health England. Human Papillomavirus (HPV) vaccine coverage in England, 2008/09 to 2013/14: A review of the full six years of the three-dose schedule. London: Public Health England; 2014

12. Kessels SJ, Marshall HS, Watson M, Braunack-Mayer AJ, Reuzel R, Tooher RL. Factors associated with HPV vaccine uptake in teenage girls: a systematic review. Vaccine. 2012;30(24):3546-56.

13. Markowitz LE, Tsu V, Deeks SL, Cubie H, Wang SA, Vicari AS, Brotherton J. Human papillomavirus vaccine introduction-the first five years. Vaccine. 2012;30:139-48. 
14. Jemal A, Simard EP, Dorell C, Noone A-M, Markowitz LE, Kohler B, Eheman C, Saraiya M, Bandi P, Saslow D, et al. Annual report to the nation on the status of cancer, 1975-2009, featuring the burden and trends in human papillomavirus (HPV)-associated cancers and HPV vaccination coverage levels. J Natl Cancer Inst. 2013;105(3):175-201.

15. Blakely T, Kvizhinadze G, Karvonen T, Pearson AL, Smith M, Wilson N. Cost-effectiveness and equity impacts of three HPV vaccination programmes for school-aged girls in New Zealand. Vaccine. 2014;32(22): 2645-56.

16. Binagwaho A, Wagner CM, Gatera M, Karema C, Nutt CT, Ngabo F. Achieving high coverage in rwanda's national human papillomavirus vaccination programme. Bull World Health Organ. 2012;90(8):623-8.

17. Dorji T, Tshomo U, Phuntsho S, Tamang TD, Tshokey T, Baussano I, Franceschi S, Clifford G. Introduction of a national HPV vaccination program into Bhutan. Vaccine. 2015;33(31):3726-30.

18. French K, Barnabas R, Lehtinen M, Kontula O, Pukkala E, Dillner J, Garnett $G$. Strategies for the introduction of human papillomavirus vaccination: modelling the optimum age-and sex-specific pattern of vaccination in Finland. Br J Cancer. 2007;96(3):514-8

19. Jit M, Choi YH, Edmunds W. Economic evaluation of human papillomavirus vaccination in the United Kingdom. BMJ. 2008;337:769.

20. Donovan B, Franklin N, Guy R, Grulich AE, Regan DG, Ali H, Wand H, Fairley CK. Quadrivalent human papillomavirus vaccination and trends in genital warts in Australia: analysis of national sentinel surveillance data. Lancet Infect Dis. 2011;11(1):39-44.

21. Hong AM, Grulich AE, Jones D, Lee CS, Garland SM, Dobbins TA, Clark JR, Harnett GB, Milross CG, O'Brien CJ, et al. Squamous cell carcinoma of the oropharynx in Australian males induced by human papillomavirus vaccine targets. Vaccine. 2010;28(19):3269-72.

22. Jit M, Chapman R, Hughes $\mathrm{O}$, Choi YH. Comparing bivalent and quadrivalent human papillomavirus vaccines: economic evaluation based on transmission model. BMJ. 2011;343:5775

23. Sinka K, Kavanagh K, Gordon R, Love J, Potts A, Donaghy M, Robertson C. Achieving high and equitable coverage of adolescent HPV vaccine in Scotland. J Epidemiol Community Health. 2014;68(1):57-63.

24. Burger EA, Sy S, Nygård M, Kristiansen IS, Kim JJ. Too late to vaccinate? The incremental benefits and cost-effectiveness of a delayed catch-up program using the 4-valent human papillomavirus vaccine in Norway. J Infect Dis. 2014;211(2):206-15.

25. Newall AT, Beutels P, Wood JG, Edmunds W, Maclntyre CR. Cost-effectiveness analyses of human papillomavirus vaccination. Lancet Infect Dis. 2007;7(4):289-96.

26. Taira AV, Neukermans CP, Sanders GD, et al. Evaluating human papillomavirus vaccination programs. Emerg Infect Dis. 2004;10(11): 1915-23.

27. Kreimer AR, Rodriguez AC, Hildesheim A, Herrero R, Porras C, Schiffman M, González P, Solomon D, Jiménez S, Schiller JT, et al. Proof-of-principle evaluation of the efficacy of fewer than three doses of a bivalent HPV16/18 vaccine. J Natl Cancer Inst. 2011;103(19):1444-51.

28. Dobson SR, McNeil S, Dionne M, Dawar M, Ogilvie G, Krajden M, Sauvageau C, Scheifele DW, Kollmann TR, Halperin SA, et al. Immunogenicity of 2 doses of HPV vaccine in younger adolescents vs 3 doses in young women: a randomized clinical trial. JAMA. 2013;309(17): 1793-802.

29. Jit M, Brisson M, Laprise J-F, Choi YH. Comparison of two dose and three dose human papillomavirus vaccine schedules: cost effectiveness analysis based on transmission model. BMJ. 2015;350:7584

30. Giuliano AR, Palefsky JM, Goldstone S, Moreira Jr ED, Penny ME, Aranda C, Vardas E, Moi H, Jessen $H$, Hillman R, et al. Efficacy of quadrivalent $H P V$ vaccine against $H P V$ infection and disease in males. $N$ Engl J Med. 2011;364(5):401-11.

31. Brisson M, Bénard É, Drolet $M$, Bogaards JA, Baussano I, Vänskä S, Jit M, Boily M-C, Smith M, Berkhof J, et al. Population-level impact, herd immunity, and elimination after human papillomavirus vaccination: a systematic review and meta-analysis of predictions from transmission-dynamic models. Lancet Public Health. 2016;1 (1):8-17.

32. Ahdieh L, Klein RS, Burk R, Cu-Uvin S, Schuman P, Duerr A, Safaeian M, Astemborski J, Daniel R, Shah K. Prevalence, incidence, and type-specific persistence of human papillomavirus in human immunodeficiency virus (HIV)-positive and HIV-negative women. J Infect Dis. 2001;184(6):682-90.
33. Hagensee ME, Kiviat N, Critchlow CW, Hawes SE, Kuypers J, Holte S, Galloway DA. Seroprevalence of human papillomavirus types 6 and 16 capsid antibodies in homosexual men. J Infect Dis. 1997;176(3):625-31

34. Nyitray AG, da Silva RJC, Baggio ML, Lu B, Smith D, Abrahamsen M Papenfuss M, Villa LL, Lazcano-Ponce E, Giuliano AR. Age-specific prevalence of and risk factors for anal human papillomavirus (HPV) among men who have sex with women and men who have sex with men: the HPV in men (HIM) study. J Infect Dis. 2011;203(1):49-57.

35. King E, Gilson R, Beddows S, Soldan K, Panwar K, Young C, Prah P, Jit M, Edmunds W, Sonnenberg P. Human papillomavirus DNA in men who have sex with men: type-specific prevalence, risk factors and implications for vaccination strategies. Br J Cancer. 2015;112(9):1585-93.

36. Matthijsse SM, Hontelez JA, Naber SK, Rozemeijer K, de Kok IM, Bakker $R$, van Ballegooijen M, van Rosmalen J, de Vlas SJ. Public health benefits of routine human papillomavirus vaccination for adults in the Netherlands: a mathematical modeling study. J Infect Dis. 2016jiw256.

37. Goldie S, Kim J, Kobus K, Goldhaber-Fiebert JD, Salomon J, O'Shea MK Bosch FX, de Sanjosé S, Franco E. Cost-effectiveness of HPV 16, 18 vaccination in Brazil. Vaccine. 2007;25(33):6257-70.

38. Armstrong EP. Prophylaxis of cervical cancer and related cervical disease: a review of the cost-effectiveness of vaccination against oncogenic HPV types. J Manag Care Pharm. 2010;16(3):217-30.

39. Kim J, Andres-Beck B, Goldie S. The value of including boys in an HPV vaccination programme: a cost-effectiveness analysis in a low-resource setting. Br J Cancer. 2007;97(9):1322-28.

40. Brisson M, van de Velde N, Franco E, Drolet M, Boily M-C. Incremental impact of adding boys to current human papillomavirus vaccination programs: role of herd immunity. J Infect Dis. 2011;204(3):372-6.

41. Kim J, Goldie S. Cost effectiveness analysis of including boys in a human papillomavirus vaccination programme in the United States. BMJ. 2009;339:3884

42. Zechmeister I, de Blasio BF, Garnett G, Neilson AR, Siebert U. Costeffectiveness analysis of human papillomavirus-vaccination programs to prevent cervical cancer in Austria. Vaccine. 2009:27(37):5133-41.

43. Pearson AL, Kvizhinadze G, Wilson N, Smith M, Canfell K, Blakely T. Is expanding HPV vaccination programs to include school-aged boys likely to be value-for-money: a cost-utility analysis in a country with an existing school-girl program. BMC Infect Dis. 2014;14(1):351.

44. Chesson HW, Ekwueme DU, Saraiya M, Dunne EF, Markowitz LE. The cost-effectiveness of male HPV vaccination in the United States. Vaccine. 2011;29(46):8443-50.

45. Smith M, Lew J-B, Walker RJ, Brotherton J, Nickson C, Canfell K. The predicted impact of HPV vaccination on male infections and male HPV-related cancers in Australia. Vaccine. 2011;29(48):9112-22.

46. Georgousakis M, Jayasinghe S, Brotherton J, Gilroy N, Chiu C, Macartney K. Population-wide vaccination against human papillomavirus in adolescent boys: Australia as a case study. Lancet Infect Dis. 2012;12(8):627-34.

47. Lin A, Ong KJ, Hobbelen P, King E, Mesher D, Edmunds W Sonnenberg P, Gilson R, Bains I, Choi YH, et al. Impact and cost-effectiveness of selective human papillomavirus vaccination of men who have sex with men. Clin Infect Dis. 2016;64(5):580-8.

48. Nielson CM, Flores R, Harris RB, Abrahamsen M, Papenfuss M, Dunne EF, Markowitz LE, Giuliano AR. Human papillomavirus prevalence and type distribution in male anogenital sites and semen. Cancer Epidemiol Biomark Prev. 2007;16(6):1107-14.

49. Tanton C, Mesher D, Beddows S, Soldan K, Clifton S, Panwar K, Field N, Mercer $\mathrm{CH}$, Johnson AM, Sonnenberg P. Human papillomavirus (HPV) in young women in Britain: Population-based evidence of the effectiveness of the bivalent immunisation programme and burden of quadrivalent and 9-valent vaccine types. Papillomavirus Res. 2017;3:36-41.

50. Datta S, Mercer CH, Keeling MJ. Capturing sexual contact patterns in modelling the spread of sexually transmitted infections: Evidence using Natsal-3. PloS ONE. 2018;13(11):0206501.

51. Nyitray AG, Lin $H-Y$, Fulp WJ, Chang M, Menezes L, Lu B, Abrahamsen M, Papenfuss M, Gage C, Galindo CM, et al. The role of monogamy and duration of heterosexual relationships on human papillomavirus (HPV) transmission. J Infect Dis. 2013;209(7):1007-15.

52. Carter JJ, Koutsky LA, Wipf GC, Christensen ND, Lee S-K, Kuypers J, Kiviat N, Galloway DA. The natural history of human papillomavirus type 16 capsid antibodies among a cohort of university women. J Infect Dis. 1996;174(5):927-36. 
53. Edelstein ZR, Carter JJ, Garg R, Winer R, Feng Q, Galloway DA, Koutsky $L A$. Serum antibody response following genital $\alpha 9$ human papillomavirus infection in young men. J Infect Dis. 2011;204(2):209-16.

54. Public Health England. Human Papillomavirus (HPV) vaccination coverage in adolescent females in England: 2014/15. London: Public Health England; 2015.

55. Public Health England. Infection report. Health Prot Report. 2016;10(22): 4-6.

56. Derkay CS. Task force on recurrent respiratory papillomas: a preliminary report. Arch Otolaryngol-Head Neck Surg. 1995;121(12):1386-91.

57. Smith JS, Lindsay L, Hoots B, Keys J, Franceschi S, Winer R, Clifford GM Human papillomavirus type distribution in invasive cervical cancer and high-grade cervical lesions: a meta-analysis update. Int J Cancer. 2007;121(3):621-32.

58. Office of National Statistics. Deaths Registered in England and Wales: 2014. London: Office for National Statistics; 2014.

59. Office of National Statistics. Cancer registration statistics, England, 2012. London: Office for National Statistics; 2012.

60. Office of National Statistics. Cancer survival in England, adults diagnosed 2008-2012 and followed up to 2013. London: Office for National Statistics; 2014.

61. Jeffreys M, Rachet B, McDowell S, Habib AG, Lepage C, Coleman MP. Survival from rectal and anal cancers in England and Wales, 1986-2001. European Journal of Cancer. 2006:42(10):1434-40.

62. Office of National Statistics. One and five year survival of patients diagnosed in 1991-95 and 1996-99: less common cancers, sex and age, England and Wales. London: Office for National Statistics; 2005.

63. Bishai D, Kashima $H$, Shah K. The cost of juvenile-onset recurrent respiratory papillomatosis. Arch Otolaryngol-Head Neck Surg. 2000;126(8):935-9.

64. Anantharaman D, Gheit T, Waterboer T, Abedi-Ardekani B, Carreira C, McKay-Chopin S, Gaborieau V, Marron M, Lagiou P, Ahrens W, et al. Human papillomavirus infections and upper aero-digestive tract cancers: the arcage study. J Natl Cancer Inst. 2013;105(8):536-45.

65. Anantharaman D, Abedi-Ardekani B, Beachler DC, Gheit T, Olshan AF, Wisniewski K, Wunsch-Filho V, Toporcov TN, Tajara EH, Levi JE, et al. Geographic heterogeneity in the prevalence of human papillomavirus in head and neck cancer. Int J Cancer. 2017;140(9):1968-75.

66. Woodhall SC, Jit M, Soldan K, Kinghorn G, Gilson R, Nathan M, Ross JD, Lacey CJN. The impact of genital warts: loss of quality of life and cost of treatment in eight sexual health clinics in the UK. Sex Transm Infect. 2011;87(6):458-63.

67. Donne A, Clarke R. Recurrent respiratory papillomatosis: an uncommon but potentially devastating effect of human papillomavirus in children. Int J STD AIDS. 2010;21(6):381-5.

68. Lanitis T, Carroll S, O'Mahony C, Charman F, Khalid J, Griffiths V, Brown $R$. The cost of managing genital warts in the UK. Int J STD AIDS. 2012;23(3):189-94.

69. Wolstenholme J, Whynes D. Stage-specific treatment costs for cervical cancer in the United Kingdom. Eur J Cancer. 1998;34(12):1889-93.

70. National Institute for Clinical Excellence. Guide to the methods of technology appraisal. London: National Institute for Clinical Excellence; 2013. https://www.nice.org.uk/Media/Default/About/what-we-do/ NICE-guidance/NICE-technology-appraisals/technology-appraisalprocesses-guide-apr-2018.pdf.

71. Review of cost-effectiveness methodology for immunisation programmes and procurements. Cost-Effectiveness Methodology for Immunisation Programmes and Procurements (CEMIPP). London: Department of Health; 2016

72. Staniszewska S, Brett J, Mockford C, Barber R. The gripp checklist: strengthening the quality of patient and public involvement reporting in research. Int J Technol Assess Health Care. 2011;27(04):391-9.

73. Wilson P, Mathie E, Keenan J, McNeilly E, Goodman C, Howe A, Poland F, Staniszewska S, Kendall S, Munday D, et al. ReseArch with Patient and Public invOlvement: a RealisT evaluation-the RAPPORT study. Health Serv Deliv Res. 2015;3(38):1-208. https://doi.org/10.3310/hsdr03380.

74. Mercer $\mathrm{CH}$, Tanton C, Prah P, Erens B, Sonnenberg P, Clifton S, Macdowall W, Lewis R, Field N, Datta J, et al. Changes in sexual attitudes and lifestyles in Britain through the life course and over time: findings from the National Surveys of Sexual Attitudes and Lifestyles (Natsal). Lancet. 2013;382(9907):1781-94.
75. Barnabas R, Laukkanen P, Koskela P, Kontula O, Lehtinen M, Garnett G. Epidemiology of HPV 16 and cervical cancer in finland and the potential impact of vaccination: mathematical modelling analyses. PLoS Med. 2006;3(5):138.

76. Smith M, Canfell K, Brotherton J, Lew J-B, Barnabas R. The predicted impact of vaccination on human papillomavirus infections in Australia. Int J Cancer. 2008;123(8):1854-63.

77. Campos NG, Burger EA, Sy S, Sharma M, Schiffman M, Rodriguez AC, Hildesheim A, Herrero R, Kim JJ. An updated natural history model of cervical cancer: derivation of model parameters. Am J Epidemiol. 2014;180(5):545-55.

78. Mesher D, Soldan K, Howell-Jones R, Panwar K, Manyenga P, Jit M, Beddows S, Gill O. Reduction in HPV 16/18 prevalence in sexually active young women following the introduction of HPV immunisation in England. Vaccine. 2013;32(1):26-32.

79. Sonnenberg P, Clifton S, Beddows S, Field N, Soldan K, Tanton C, Mercer CH, da Silva FC, Alexander S, Copas AJ, et al. Prevalence, risk factors, and uptake of interventions for sexually transmitted infections in Britain: findings from the National Surveys of Sexual Attitudes and Lifestyles (Natsal). Lancet. 2013;382(9907):1795-806.

80. Drolet M, Bénard É, Boily M-C, Ali H, Baandrup L, Bauer H, Beddows S, Brisson J, Brotherton J, Cummings T, et al. Population-level impact and herd effects following human papillomavirus vaccination programmes: a systematic review and meta-analysis. Lancet Infect Dis. 2015;15(5): 565-80.

81. Ryding J, French K, Naucler P, Barnabas R, Garnett G, Dillner J. Seroepidemiology as basis for design of a human papillomavirus vaccination program. Vaccine. 2008;26(41):5263-8.

82. Beachler DC, Jenkins G, Safaeian M, Kreimer AR, Wentzensen N. Natural acquired immunity against subsequent genital human papillomavirus infection: a systematic review and meta-analysis. J Infect Dis. 2016;213(9):1444-54.

83. Joint Committee on Vaccination and Immunisation. Statement on HPV vaccination. 2018. https://assets.publishing.service.gov.uk/government/ uploads/system/uploads/attachment_data/file/726319/ JCVI_Statement_on_HPV_vaccination_2018.pdf. Accessed 22 Oct 2018.

84. Szarewski A, Skinner SR, Garland SM, Romanowski B, Schwarz TF, Apter D, Chow S-N, Paavonen J, Del Rosario-Raymundo MR, Teixeira JC, et al. Efficacy of the HPV-16/18 AS04-adjuvanted vaccine against low-risk HPV types (PATRICIA randomized trial): an unexpected observation. J Infect Dis. 2013;208(9):1391-6.

85. Elfström KM, Lazzarato F, Franceschi S, Dillner J, Baussano I. Human papillomavirus vaccination of boys and extended catch-up vaccination: effects on the resilience of programs. J Infect Dis. 2015;213(2):199-205.

86. Colucci R, Hryniuk W, Savage C. HPV vaccination programs in Canada; Are we hitting the mark? 2008. http://www.canceradvocacy.ca/ reportcard/2008/HPV\%20Vaccination\%20Programs\%20in\%20Canada. pdf. Accessed 7 Nov 2017.

87. Canadian Partnership Against Cancer. The 2016 Cancer System Performance Report. 2016. https://www.systemperformance.ca/report/ 2016-cancer-system-performance-report/. Accessed 25 Nov 2018.

88. Qendri V, Bogaards JA, Berkhof J. Health and economic impact of a tender-based, sex-neutral human papillomavirus 16/18 vaccination program in the Netherlands. J Infect Dis. 2017;216(2):210-9.

89. Borget I, Abramowitz L, Mathevet P. Economic burden of HPV-related cancers in france. Vaccine. 2011;29(32):5245-9.

90. Marty R, Roze S, Bresse X, Largeron N, Smith-Palmer J. Estimating the clinical benefits of vaccinating boys and girls against HPV-related diseases in Europe. BMC Cancer. 2013;13(1):1.

91. Mercer CH, Fenton KA, Wellings K, Copas AJ, Erens B, Johnson AM. Sex partner acquisition while overseas: results from a British national probability survey. Sex Transm Infect. 2007;83(7):517-22.

92. Ronco G, Dillner J, Elfström KM, Tunesi S, Snijders PJ, Arbyn M, Kitchener H, Segnan N, Gilham C, Giorgi-Rossi P, et al. Efficacy of HPV-based screening for prevention of invasive cervical cancer: follow-up of four european randomised controlled trials. Lancet. 2014;383(9916):524-32.

93. Castanon A, Landy R, Sasieni P. By how much could screening by primary human papillomavirus testing reduce cervical cancer incidence in England? J Med Screen. 2017;24(2):110-2. 
94. Landy R, Windridge P, Gillman MS, Sasieni PD. What cervical screening is appropriate for women who have been vaccinated against high risk HPV? a simulation study. Int J Cancer. 2018;142(4):709-18.

95. Hall MT, Simms KT, Lew J-B, Smith M, Brotherton J, Saville M, Frazer $\mid H$ Canfell K. The projected timeframe until cervical cancer elimination in Australia: a modelling study. Lancet Public Health. 2019;4(1):19-27.

96. Desai S, Chapman R, Jit M, Nichols T, Borrow R, Wilding M, Linford C, Lowndes CM, Nardone A, Pebody R, et al. Prevalence of human papillomavirus antibodies in males and females in England. Sex Transm Dis. 2011;38(7):622-9.

97. Mollers M, Hein JB, Henrike JV, Audrey JK, van den Broek Ingrid V, van Bergen Jan E, Antoinette AB, Petra FW, Christian JH, Chris JM, et al. Prevalence, incidence and persistence of genital HPV infections in a large cohort of sexually active young women in the Netherlands. Vaccine. 2013;31(2):394-401.

98. Tanton C, Soldan K, Beddows S, Mercer CH, Waller J, Field N, Clifton S, Copas AJ, Panwar K, Manyenga P, et al. High-risk human papillomavirus (HPV) infection and cervical cancer prevention in Britain: Evidence of differential uptake of interventions from a probability survey. Cancer Epidemiol Prev Biomark. 2015;24(5):842-53.

99. Malagón T, Joumier V, Boily M-C, Van de Velde N, Drolet M, Brisson M. The impact of differential uptake of HPV vaccine by sexual risks on health inequalities: a model-based analysis. Vaccine. 2013;31(13):1740-7.

100. Drolet M, Boily M-C, Greenaway C, Deeks SL, Blanchette C, Laprise J-F, Brisson M. Sociodemographic inequalities in sexual activity and cervical cancer screening: implications for the success of human papillomavirus vaccination. Cancer Epidemiol Biomark Prev. 2013;22(4):641-52.

101. Sacks RJ, Copas AJ, Wilkinson DM, Robinson AJ. Uptake of the HPV vaccination programme in England: a cross-sectional survey of young women attending sexual health services. Sex Transm Infect. 2014;90(4): 315-21.

102. Hahné S, Ramsay M, Balogun K, Edmunds W, Mortimer P. Incidence and routes of transmission of hepatitis B virus in England and Wales, 1995-2000: implications for immunisation policy. J Clin Virol. 2004;29(4): 211-20.

103. Lehtinen M, Dillner J. Clinical trials of human papillomavirus vaccines and beyond. Nat Rev Clin Oncol. 2013;10(7):400.

104. Rositch AF, Koshiol J, Hudgens MG, Razzaghi H, Backes DM, Pimenta JM, Franco E, Poole C, Smith JS. Patterns of persistent genital human papillomavirus infection among women worldwide: a literature review and meta-analysis. Int J Cancer. 2013;133(6):1271-85.

105. Johnson AM, Mercer CH, Erens B, Copas AJ, McManus S, Wellings K, Fenton KA, Korovessis C, Macdowall W, Nanchahal K, et al. Sexual behaviour in Britain: partnerships, practices, and hiv risk behaviours. Lancet. 2001;358(9296):1835-42.

106. Wellings K, Johnson AM. Framing sexual health research: adopting a broader perspective. Lancet. 2013;382(9907):1759-62.

107. Leng T, Keeling MJ. Concurrency of partnerships, consistency with data, and control of sexually transmitted infections. Epidemics. 2018;25:35-46.

108. Brisson M, Laprise J-F, Drolet M, Van de Velde N, Franco E, Kliewer EV, Ogilvie G, Deeks SL, Boily M-C. Comparative cost-effectiveness of the quadrivalent and bivalent human papillomavirus vaccines: a transmission-dynamic modeling study. Vaccine. 2013;31(37):3863-71.

109. Introcaso CE, Dunne EF, Hariri S, Panicker G, Unger ER, Markowitz LE. Prevaccine era human papillomavirus types 6, 11, 16 and 18 seropositivity in the USA, National Health and Nutrition Examination Surveys, 2003-2006. Sex Transm Infect. 2014;90(6):505-8.

110. Hariri S, Dunne EF, Sternberg M, Unger ER, Meadows KS, Karem KL, Markowitz LE. Seroepidemiology of human papillomavirus type 11 in the United States: results from the third National Health And Nutrition Examination Survey, 1991-1994. Sex Transm Dis. 2008;35(3):298-303.

111. Stone KM, Karem KL, Sternberg MR, McQuillan GM, Poon AD, Unger ER, Reeves WC. Seroprevalence of human papillomavirus type 16 infection in the United States. J Infect Dis. 2002;186(10):1396-402.

112. Jit M, Vyse A, Borrow R, Pebody R, Soldan K, Miller E. Prevalence of human papillomavirus antibodies in young female subjects in England. Br J Cancer. 2007;97(7):989-91

113. Castro FA, Dominguez A, Puschel K, Van De Wyngard V, Snijders PJ, Franceschi S, Pawlita M, Ferreccio C. Serological prevalence and persistence of high-risk human papilloma infection among women in Santiago, Chile. BMC Infect Dis. 2014;14(1):361.
114. Sargent A, Bailey A, Almonte M, Turner A, Thomson C, Peto J, Desai M, Mather J, Moss S, Roberts C, et al. Prevalence of type-specific HPV infection by age and grade of cervical cytology: data from the ARTISTIC trial. Br J Cancer. 2008;98(10):1704-9.

115. Giuliano AR, Lu B, Nielson CM, Flores R, Papenfuss M, Lee J-H, Abrahamsen M, Harris RB. Age-specific prevalence, incidence, and duration of human papillomavirus infections in a cohort of 290 US men. J Infect Dis. 2008;198(6):827-35.

116. Kavanagh K, Sinka K, Cuschieri K, Love J, Potts A, Pollock KG, Cubie H, Donaghy M, Robertson C. Estimation of HPV prevalence in young women in Scotland; monitoring of future vaccine impact. BMC Infect Dis. 2013;13(1):519.

117. Brown R, Breugelmans J, Theodoratou D, Benard S. Costs of detection and treatment of cervical cancer, cervical dysplasia and genital warts in the UK. Curr Med Res Opin. 2006;22(4):663-70.

118. Gold MR, Franks P, McCoy Kl, Fryback DG. Toward consistency in cost-utility analyses: using national measures to create condition-specific values. Med Care. 1998;36(6):778-92.

119. Rogers S, Miller R, Ali K, Minhas A, Williams H, Lowe D. Patients' perceived health status following primary surgery for oral and oropharyngeal cancer. Int J Oral Maxillofac Surg. 2006;35(10):913-9.

120. Insinga RP, Glass AG, Myers ER, Rush BB. Abnormal outcomes following cervical cancer screening: event duration and health utility loss. Med Dec Making. 2007;27(4):414-22.

121. Korfage IJ, Essink-Bot M-L, Mols F, van de Poll-Franse L, Kruitwagen R, van Ballegooijen M. Health-related quality of life in cervical cancer survivors: a population-based survey. Int J Radiat Oncol* Biol* Phys. 2009;73(5):1501-9.

122. Trottier H, Ferreira S, Thomann P, Costa MC, Sobrinho JS, Prado JCM, Rohan TE, Villa LL, Franco E. Human papillomavirus infection and reinfection in adult women: the role of sexual activity and natural immunity. Cancer Res. 2010;70(21):8569-77.
Ready to submit your research? Choose BMC and benefit from:

- fast, convenient online submission

- thorough peer review by experienced researchers in your field

- rapid publication on acceptance

- support for research data, including large and complex data types

- gold Open Access which fosters wider collaboration and increased citations

- maximum visibility for your research: over 100M website views per year

At $\mathrm{BMC}$, research is always in progress.

Learn more biomedcentral.com/submissions 